\title{
R3 Teste de quantificação de CV HCV desenvolvido em Bio- Manguinhos: avaliação do desempenho frente a amostras de pacientes em tratamento com AlfaPeg-Interferona
}

Elisabete Andrade ${ }^{1}$, Daniele Rocha ${ }^{1}$, Marcela Fontana1, Antonio G. P. Ferreira ${ }^{1}$, Ana Carolina de Andrade ${ }^{1}$, Roberta Mílan¹, Patrícia Alvarez ${ }^{1}$

${ }^{1}$ Bio-Manguinhos, Fiocruz, Rio de Janeiro, RJ

Introdução: $\mathrm{O}$ vírus da Hepatite C (HCV) leva à inflamação crônica do fígado, atingindo 3,0\% da população mundial. A quantificação da carga viral (QCV) do HCV circulante em plasma humano representa uma ferramenta importante para o prognóstico e o acompanhamento clínico do paciente, auxiliando na administração, duração e monitoramento do tratamento com alfa peg interferona. Os ensaios comerciais destinados à QCV do HCV no Brasil têm custos abusivos e a obtenção de uma alternativa nacional possibilitará ampliar significativamente o acesso da população.

Objetivo: Avaliar o desempenho do método de QCV do HCV de pacientes portadores de HCV utilizando o teste desenvolvido e validado por Bio-Manguinhos/FIOCRUZ, dentro dos padrões estabelecidos na RDC n²7/2012.

Metodologia: O teste de QCV é um ensaio duplex contendo alvos para HCV e Calibrador Interno (Patente Fiocruz), com base na plataforma de PCR em tempo real utilizando uma curva padrão (VLP-virus like partical) com a inserção de parte do genoma do HCV. Foram testadas amostras de pacientes $(n=191)$ com sorologia HCV positiva das regiões Sul e Sudeste do Brasil, em tratamento com alfa peg interferona. A CV HCV foi acompanhada desde a visita antes da administração com alfa peg interferona, até a $12^{\underline{a}}$ ou $24^{\mathrm{a}}$ semana após o início do tratamento, dependendo da resposta virológica de cada individuo: Precoce Parcial, com redução da CV HCV em 2 log ou mais na semana 12; Precoce Completa, na qual pacientes positivos na semana 4 e na semana 12 encontram-se indetectáveis; Lenta com a CV HCV positiva na 12 a semana e negativa na $24^{a}$ semana, ou não respondedor ao tratamento, quando sem redução da CV HCV em pelo menos 2 log, na $12^{a}$ semana após início do tratamento.

Resultados: Todas as amostras foram processadas com o método de QCV desenvolvido e validado por Bio-Manguinhos, determinando e caracterizando, na 12a semana de tratamento, os pacientes da seguinte forma: $51 \%$ apresentaram RVP completa, $21 \%$ RVP parcial e $28 \%$ não responderam ao tratamento. Em paralelo, foram testadas $30 \%$ das amostras $(n=60)$, com o kit COBAS Taqman HCV Test (v2.0). Os resultados foram comparados e a média de variação foi inferior a 0,4 log. Os resultados obtidos com a QCV HCV auxiliaram na indicação da eficácia da terapia com alfa peg interferona em pacientes portadores 
de HCV, onde $61 \%(n=117)$ dos tratados tiveram CV HCV não detectada em até 24 semanas.

Conclusão: A avaliação do desempenho do teste de QCV de HCV desenvolvido e validado em Bio-Manguinhos com 191 amostras foi considerada satisfatória e adequada sob os aspectos técnico, operacionais e de funcionalidade. Os resultados obtidos indicam que 0 potencial produto após registro junto aos Órgãos Regulatórios servirá como alternativa eficaz e de menor custo a ser ofertado para a população brasileira.

Palavras-Chave: HCV, Carga Viral, Quantificação 